\title{
A Case of Intranasal Meningocele
}

\author{
Mamatha Bhat*
}

\section{INTRODUCTION}

Intranasal meningoceles occur as a result of herniation of the meninges into the nasal cavity through a defect in the cribriform plate. These are commonly found in the pediatric population due to a congenital defect in the skull base. Intranasal meningoceles are very rare in adults, and tend to arise only when engendered by trauma. Here, we present the case of a patient with seemingly unprovoked intranasal meningocele.

\section{CASE REPORT}

Mr. M. is a 23 -year-old labourer at a lignite factory who presented with left-sided nasal obstruction and watery discharge which he had been experiencing onand-off for the past 5 years. He attributed the obstruction to a mass in his left nostril, and said he would often breathe through his mouth. Other than an episode of pyogenic meningitis 9 years prior to the present complaint, this patient had been relatively healthy. He had no history of epistaxis, head or nasal trauma, anosmia, headache or visual disturbances. Constitutional symptoms such as anorexia and weight loss were absent.

On rhinoscopic examination, the left nasal cavity was found to contain a pale polypoidal mass with prominent blood vessels. The mass appeared to arise from the roof of the nasal cavity with no other points of attachment, and almost completely obstructed the nasal cavity. It descended to below the level of the inferior turbinate. No active discharge was observed. In addition, there was septal deviation to the right.

At this point, the clinician would suspect the following as part of the differential diagnosis:

*To whom correspondence should be addressed: mbhat1@pobox.mcgill.ca antrochoanal polyp, inverted papilloma, angiofibroma, intranasal menigocele, nasal glioma and congenital tumours such as neuroblastoma (1). The clinical presentation strongly suggested the diagnosis of polyp for this nasal mass.

A CT scan of the paranasal sinuses showed that they were clear. A cystic mass attached to the roof of the nasal cavity and causing right septal deviation could be seen. No bone erosion was apparent, and no abnormalities at the intracranial or orbital levels were noted. Routine blood investigations turned out to be normal.

\section{TREATMENT}

Due to the possibility of this nasal mass being a meningocele, certain precautionary measures were taken as part of endoscopic surgery to treat this patient. Of particular importance was irrigation of the nose with a solution of clindamycin to decrease bacteria within the operative field so as to reduce the potential for intracranial seeding from nasal flora.

An aspirate of the nasal mass was taken and sent for analysis. Rather than grasping and avulsing the mass, the upper portion of the polyp was cut, leaving a small sleeve. Once the mass was surgically excised, the source of the fluid leak was closed in layers: fat, then temporalis muscle/fascia. The temporalis fascia was used to seal the defect and served as a scaffold for fibrous ingrowth. Through the measurement of glucose content of the mass aspirate, it was determined that the fluid was cerebrospinal fluid (CSF). Pathological analysis of the tissue was characteristic of the meninges. These two findings correlated with the diagnosis of intranasal meningocele.

Post-operative management of this patient consisted of antibiotics (amoxicillin/clavulinic acid), acetazolamide and bedrest in the head-up position. The nasal pack was removed after 5 days. Diagnostic 
endoscopy on the 7th post-operative day showed that the graft was in place. No CSF leak was observed, and the patient did not complain of rhinorrhea subsequent to surgery.

\section{DISCUSSION}

Intranasal meningocoeles occur secondary to meningeal herniation through a defect in the floor of the anterior cranial fossa. In addition, there is a disruption in the arachnoid and dura mater, leading to a CSF leak. In a patient with intranasal meningocele, this is manifested as CSF rhinorrhea (2).

A CSF pressure gradient that is greater than the tensile strength of the disrupted tissue is a contributing factor in meningeal herniation. This can occur in the context of intracranial hypertension and results in exertion of hydrostatic pressure at anatomically weakened sites within the skull base (3). When elevated intracranial pressure is present, the weakest anatomic points in the periphery of the central nervous system (optic nerve sheath, the cribriform plate, the sellar diaphragm, and any other bony dehiscences in the anterior or middle cranial fossae) can act as potential release valves for the high pressure (4).

There are various possible etiologies of CSF leaks: spontaneous, accidental trauma, surgical trauma, congenital, and tumours.

The most common etiology of CSF leaks is accidental trauma from closed head injury; such leaks occur in around $1 \%$ to $3 \%$ of all closed head injuries. In such instances, CSF leaks usually begin within 48 hours, and 95\% of them manifest within 3 months of injury (5).

The detection of CSF fistulae is best made these days using Computed Tomographic Cisternography (CTC) (5). Such instrumentation is not readily available in hospitals of developing countries, thus the visualization and detection of herniation in this case was made using CT scanning.

Other methods used to localize CSF leakage include plain skull films, positron emission tomography, introduction of dyes by lumbar puncture, digital fluoroscopy and magnetic resonance imaging (5).

Intraoperatively, one can identify the site of a leak through the immunoelectrophoretic identification of CSF-specific marker proteins such as B2-transferrin. The sodium fluorescein test perioperatively enables precise localization of the defect and allows for confirmation of complete sealing of the leak (6).

Intranasal meningocele can be complicated by meningitis, as the intracranial contents are exposed to intranasal organisms such as $\mathrm{S}$. pneumoniae and $\mathrm{H}$. influenzae.

The patient's own episode of pyogenic meningitis 9 years ago was likely attributable to such a communication with intranasal contents. Intranasal meningoceles, as mentioned earlier, present most commonly in childhood as the result of a congenital weakness in the cribriform plate. It is probable that our patient had such congenital weakness to a lesser extent than most individuals. It is also possible that some minor trauma contributed to herniation through a preexisting weak cribriform plate. The herniation through the cribriform plate defect was likely minimal when the patient suffered an episode of pyogenic meningitis, which might be why the patient did not feel nasal obstruction at the time.

Surgical repair of CSF leak using a frontal craniotomy approach was started by Dandy in 1926. This was followed by extracranial and transnasal approaches in the 1950s. Endoscopic technique, which was being used principally for sinus surgery, was first attempted in the repair of CSF leaks in $1981(8,9)$. This has evolved to the present-day endoscopic technique which offers greater benefits by way of visualization, no scar remnant, lower morbidity and no adverse effect on the sense of smell. The literature shows that the success rate with such an approach is 86 to $97 \%(10,11)$.

Certain medical centers in the U.S. have begun to implement computer-assisted image-guided surgery techniques, which have ensured more accurate and precise closure of cribriform plate defects.

With respect to post-operative management, nasal packing is kept in place in order to compress the fascia against the recipient bed. Bedrest in the head-up position ensures that CSF pressure at the anterior skull base is decreased. Acetazolamide is used to decrease ICP, thus preventing herniation. It is a diuretic that diminishes CSF production by $48 \%$ (12).

In summary, patient presentation with nasal mass and rhinorrhea has its own set of differential diagnoses. Intranasal meningocele, although relatively rare, comes under this differential. CSF rhinorrhea is a diagnostic challenge; if not recognized, it can lead to devastating complications.

\section{REFERENCES}

1. Health Canada. Statistics Canada microdata tape Canadian Community Health Survey, 2000. Available at: http://www.phac-aspc.gc.ca/publicat/ac/ac_3e.html. Accessibility verified April 17, 2005.

2. Intercontinental Medical Statistics Canada. 1999. Available at: http://www.imshealthcanada.com/htmen/4_2_1_15.htm. Accessibility verified April 17, 2005.

3. Intercontinental Medical Statistics Canada. 2003. Available at: http://www.imshealthcanada.com/htmen/1_0_12.htm. Accessibility verified April 17, 2005.

4. Luong C, Miller A, Barnett J, et al. The structure of human cyclooxygenase-2; conservation and flexibility of the NSAID binding site. Nat Struct Biol 1996; 3:927-33.

5. Hawkey CJ. COX-2 inhibitors. Lancet 1999; 353(9149): 30714. 
6. Gierse JK, McDonald JJ, Hauser SD, et al. A single amino acid difference between cyclooxygenase-1 (COX-1) and -2 (COX-2) reverses the selectivity of COX-2 specific inhibitors. J Biol Chem 1996; 271:15810-4.

7. Chandrasekharan NV, Dai $\mathrm{H}$, Roos KL, et al. COX-3, a cyclooxygenase-1 variant inhibited by acetaminophen and other analgesic/antipyretic drugs: cloning, structure, and expression. Proc Natl Acad Sci U S A 2002; 99(21): 13926-31.

8. Henry D, Lim LL, Garcia Rodriguez LA, et al. Variability in risk of gastrointestinal complications with individual non-steroidal anti-inflammatory drugs: results of a collaborative metaanalysis. BMJ 1996; 312(7046):1563-6.

9. Bombardier C, Laine L, Reicin A, et al. Comparison of upper gastrointestinal toxicity of rofecoxib and naproxen in patients with rheumatoid arthritis. N Engl J Med 2000; 343: 1520-8.

10. Mukherjee D, Nissen SE, Topol EJ. Risk of cardiovascular events associated with selective COX-2 inhibitors. JAMA 2001; 286: 954-9.

11. Food and Drug Administration Advisory Committee. Cardiovascular Safety Review of Rofecoxib. 2001. Available at: http://www.fda.gov/ohrms/dockets/ac/01/briefing/3677b2_06_c ardio.pdf. Accessibility verified April 17, 2005.

12. FitzGerald GA. Coxibs and Cardiovascular Disease. N Engl J Med 2004; 351:1709-11.

13. Sibbald B. Rofecoxib (Vioxx) voluntarily withdrawn from market. CMAJ 2004; 171(9):1027-8.

14. Canadian Broadcasting Corporation. 2004. Available at: http://www.cbc.ca/story/science/national/2004/11/04/vioxx_cel ebrex041.html. Accessibility verified April 17, 2005.

15. Silverstein FE, Faich G, Goldstein JL, et al. Gastrointestinal toxicity with celecoxib vs nonsteroidal anti-inflammatory drugs for osteoarthritis and rheumatoid arthritis: the CLASS study: A randomized controlled trial. Celecoxib Long-term Arthritis Safety Study. JAMA 2000; 284(10):1247-55.

16. Lu HL. Statistical Reviewer Briefing Document for the Advisory Committee. Available at: http://www.fda.gov/ ohrms/dockets/ac/01/briefing/3677b1_04_stats.doc. Accessibility verified April 17, 2005.
17. FitzGerald GA, Patrono C. The coxibs, selective inhibitors of cyclooxygenase-2. N Engl J Med 2001; 345(6): 433-42.

18. Warner TD, Giuliano F, Vojnovic I, et al. Nonsteroid drug selectivities for cyclo-oxygenase-1 rather than cyclo-oxygenase2 are associated with human gastrointestinal toxicity: a full in vitro analysis. Proc Natl Acad Sci U S A 1999; 96:7563-8 .

19. Couzin J. Clinical trials. Halt of Celebrex study threatens drug's future, other trials. Science 2004; 306(5705):2170.

20. Topol EJ. Arthritis medicines and cardiovascular events--"house of coxibs". JAMA 2005; 293(3):366-8.

21. Caughey GE, Cleland LG, Penglis PS, et al. Roles of cyclooxygenase (COX)-1 and COX-2 in prostanoid production by human endothelial cells: selective up-regulation of prostacyclin synthesis by COX-2. J Immunol 2001; 167(5): 2831-8.

22. Dancu MB, Berardi DE, Vanden Heuvel JP, et al. Asynchronous shear stress and circumferential strain reduces endothelial NO synthase and cyclooxygenase-2 but induces endothelin- 1 gene expression in endothelial cells. Arterioscler Thromb Vasc Biol 2004; 24(11):2088-94 .

23. Warner TD, Vojnovic I, Giuliano F, et al. Cyclooxygenases 1, 2, and 3 and the production of prostaglandin I2: investigating the activities of acetaminophen and cyclooxygenase-2-selective inhibitors in rat tissues. J Pharmacol Exp Ther 2004; 310(2): 642-7.

24. Ott E, Nussmeier NA, Duke PC, et al. Efficacy and safety of the cyclooxygenase 2 inhibitors parecoxib and valdecoxib in patients undergoing coronary artery bypass surgery. J Thorac Cardiovasc Surg 2003; 125:1481-92.

25. Nussmeier NA, Whelton AA, Brown MT, et al. Complications of the COX-2 inhibitors parecoxib and valdecoxib after cardiac surgery. N Engl J Med 2005; 352(11):1081-91.

26. Food and Drug Administration. Alert for Healthcare Professionals Valdecoxib (marketed as Bextra), 2005. Available at: http://www.fda.gov/cder/drug/InfoSheets/HCP/ valdecoxibHCP.htm. Accessibility verified April 17, 2005.

27. Sibbald B. Pfizer to withdraw valdecoxib (Bextra) at Health Canada's request. CMAJ 2005; 172(10):e1298.

Mamatha Bhat is a first-year Family Medicine resident at McGill University. She obtained a BSc in Microbiology \& Immunology in 2001, followed by the MDCM degree in 2005 at McGill. She is the past recipient of a CIHR student bursary for research in pedopsychiatry. This case report was written during a summer elective in otolaryngology in India, with the encouragement of her supervisor Dr. Krishnakumar. 